\title{
Determination of Ore Contents of Rare Earth Elements in Geological Samples by Atomic Emission Spectrometry with Arc Two-Jet Plasmatron
}

\author{
Aleksei S. Shavekin*, Svetlana B. Zayakina, \\ Bagai-ool Yu. Saryg-ool, Irina N. Myagkaya, \\ Sergey M. Zhmodik and Elena V. Lazareva \\ Sobolev Institute of Geology and Mineralogy SB RAS \\ Novosibirsk, Russian Federation
}

\begin{abstract}
The paper presents the results of determination of the ore contents of rare earth elements (REE) in geological samples by atomic emission spectrometry with arc two-jet plasmatron, which allows to analyze solid-phase samples asa fine powders. We studied a niobium-rare earth ore sampled at the Buranniy site of the Tomtor deposit (Arctic Siberia, Russia). The results for all REEs, except for $\mathrm{Tb}, \mathrm{Yb}$ and $\mathrm{Lu}$, are consistent with the ICP-MS data. It is shown that the use of several analytical lines at the same time in the determination of REE significantly increases the determination accuracy and reliability of the results.
\end{abstract}

Keywords: arc two-jet plasmatron, atomic emission spectrometry, rare earth elements, Tomtor.

Citation: Shavekin A.S., Zayakina S.B., Saryg-ool B.Yu., Myagkaya I.N., Zhmodik S.M., Lazareva E.V. Determination of ore contents of rare earth elements in geological samples by atomic emission spectrometry with arc two-jet plasmatron, J. Sib. Fed. Univ. Chem., 2021, 14(1), 59-71. DOI: 10.17516/1998-2836-0216

(C) Siberian Federal University. All rights reserved

This work is licensed under a Creative Commons Attribution-NonCommercial 4.0 International License (CC BY-NC 4.0).

* Corresponding author E-mail address: shavekin@igm.nsc.ru

ORCID: 0000-0002-8611-2542 (Saryg-ool B.) 


\title{
Определение рудных содержаний редкоземельных элементов \\ в геологических образцах методом \\ атомно-эмиссионной спектрометрии \\ с дуговым двухструйным плазмотроном
}

\author{
А. С. Шавекин, С. Б. Заякина, Б. Ю. Сарыг-оол, \\ И.Н. Мягкая, С. М. Жмодик, Е. В. Лазарева \\ Институт геологии и минералогии им. В. С. Соболева СО РАН \\ Российская Федерачия, Новосибирск
}

\begin{abstract}
Аннотация. В работе приведены результаты определения рудных содержаний редкоземельных элементов (РЗЭ) в геологических образцах методом атомно-эмиссионной спектрометрии с дуговым двухструйным плазматроном, позволяющей проводить анализ твердофазных образцов в виде мелкодисперсных порошков. Изучался образец ниобий-редкоземельной руды, отобранный на участке Буранный Томторского месторождения (Арктическая Сибирь, Россия). Результаты анализа по всем Р3Э, за исключением Tb, Ybu Lu, согласуются с данными ИСП-МС-анализа. Показано, что использование одновременно нескольких аналитических линий при определении РЗЭ значительно повышает точность определения и достоверность результатов.
\end{abstract}

Ключевые слова: дуговой двухструйный плазматрон, атомно-эмиссионная спектрометрия, редкоземельные элементы, Томтор.

Цитирование: Шавекин, А.С. Определение рудных содержаний редкоземельных элементов в геологических образцах методом атомно-эмиссионной спектрометрии с дуговым двухструйным плазмотроном / А.С. Шавекин, С. Б. Заякина, Б. Ю. Сарыг-оол, И.Н. Мягкая, С. М. Жмодик, Е. В. Лазарева // Журн. Сиб. федер. ун-та. Химия, 2021, 14(1). С. 59-71. DOI: $10.17516 / 1998-2836-0216$

\section{Введение}

Атомно-эмиссионная спектрометрия (АЭС) является мощным инструментом для определения элементного состава образцов различной природы. В качестве источников возбуждения спектров (ИВС) в АЭС применяют индуктивно связанную плазму, дугу постоянного тока, дуговую двухструйную плазму, микроволновую плазму и др. [1]. Несмотря на то что массовое распространение получила АЭС с индуктивно связанной плазмой, интерес вызывают установки с ИВС, позволяющие проводить элементный анализ непосредственно из твердофазных образцов без предварительной химической пробоподготовки [2], что позволит сократить время анализа и уменьшить систематическую погрешность, вносимую в процессе пробоподготовки [3].

Инструментальное определение содержаний редкоземельных элементов (РЗЭ) в геологических образцах является актуальной задачей [4-6]. Сложность и длительность химической пробоподготовки геологических образцов для определения РЗЭ, вызванная, прежде всего, упорностью минералов-носителей РЗЭ [7], подтолкнуло исследователей к разработке методов и установок, позволяющих проводить прямой элементный анализ твердых образцов [8-10].

$$
-60-
$$


Атомно-эмиссионная спектрометрия с дуговым двухструйным плазматроном (ДДП-АЭС) дает возможность проводить анализ твердофазных образцов в виде мелкодисперсных порошков [10]. Возможности ДДП-АЭС для определения элементного состава различных геологических образцов показаны во многих работах [2,11-16], однако практически не исследованы возможности метода для определения всего спектра РЗЭ. Типичные пределы обнаружения для РЗЭ находятся на уровне $10^{-5}-10^{-7}$ масс.\% в зависимости от выбранной аналитической линии элемента и химического состава образца $[11,12]$. Перспективным является применение данного метода для анализа руд редкоземельных элементов с содержаниями РЗЭ на уровне от 0.1 до 10 масс.\%, что позволит избежать трудностей, связанных с химической пробоподготовкой ультрабогатых руд, «заражения» прибора при использовании других высокочувствительных методов (например, ИСП-МС), и снижает погрешность при значительных разбавлениях.

Кроме того, разработка экспрессного инструментального метода определения РЗЭ с широким диапазоном содержаний элементов (от $10^{-5}$ до 10 масс.\%) в образцах и низкими пределами обнаружения может быть очень полезной и востребованной в связи с необходимостью массового определения РЗЭ при поисках и разведке месторождений РЗЭ. Особенно актуально в случаях, когда анализируются пробы с резко контрастными содержаниями элементов, а также в технологических процессах обогащения и извлечения РЗЭ. В данной работе исследовалась принципиальная возможность определения рудных содержаний РЗЭ в геологических образцах методом атомно-эмиссионной спектрометрии с дуговым двухструйным плазматроном.

\section{Экспериментальная часть}

\section{Образеи руды}

Для исследования использовали образец руды (ТМ-96), отобранный на участке Буранный Томторского ниобий-редкоземельного месторождения и представляющий собой богатые ниобий-редкоземельные руды [17]. Минеральный состав руд включает более 80 минералов: оксиды (пирохлор, гетит, гематит, рутил, ильменорутил), фосфаты (монацит, минералы группы крандаллита, фторапатит, ксенотим), карбонаты (сидерит), сульфиды (пирит, галенит, сфалерит, халькопирит), силикаты (каолинит, гидрослюды) [18, 19]. Но основу руд составляют гётит, монацит и минералы группы крандаллита, пирохлор, оксиды Ті. Руды тонкослоистые и криптозернистые, более 70 \% зёрен имеют размер $<1 \mu \mathrm{m}$ [17]. Исследуемый образец ТМ-96 по основному минеральному составу очень схож с типичными рудами. Отличие состоит в значительном содержании в образце ксенотима, что обеспечивает более высокое, чем в типичных рудах содержание иттрия $\left(\mathrm{Y}_{2} \mathrm{O}_{3}-2 \%\right.$, тогда как в среднем в рудах содержится $0.75 \%$ ) и тяжёлых лантаноидов. Содержания $\mathrm{REE}_{2} \mathrm{O}_{3}$ составляют $7.2 \%, \mathrm{Nb}_{2} \mathrm{O}_{5}-1.2 \%, \mathrm{P}_{2} \mathrm{O}_{5}-7.6 \%, \mathrm{Fe}_{2} \mathrm{O}_{3}-21.2 \%$, $\mathrm{TiO}_{2}-2.7 \%$.

\section{Аппаратура}

Исследование для данной работы проводилось на установке с дуговым двухструйным плазматроном и спектрометром ДФС-458C [20, 21], на котором установлен многоканальный анализатор атомно-эмиссионных спектров (МАЭС) [22], разработанный и изготовленный фирмой ВМК «Оптоэлектроника» (г. Новосибирск). В установке применялся аргоновый плазматрон, состоящий из двух идентичных электродных горелок [23, 24]. 
На щель спектрометра проецируется аналитическая зона (рис. 1), образующаяся посередине между двумя плазменными горелками, в результате слияния трех газовых струй (двух горячих плазменных и одной холодной, транспортирующей пробу). Исследуемая проба представляет собой мелкодисперсный порошок с крупностью частиц не более 0.074-0.076 мм, который вводится в плазменный поток между струями плазмы (рис. 1). Масса навески составляла

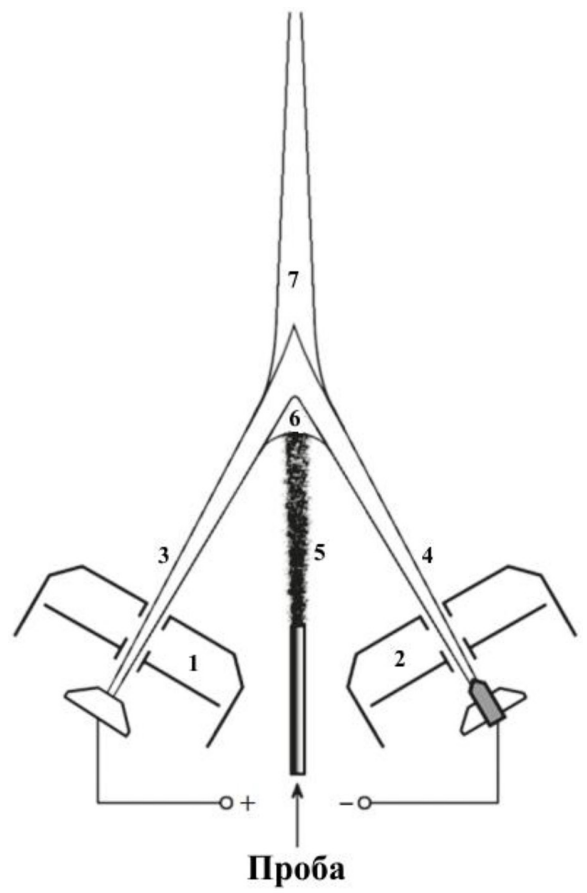

Рис. 1. Электродный блок плазматрона и аналитические зоны плазмы: 1, 2 - плазменные горелки; 3, 4 - потоки плазмообразующих струй; 5 - поток транспортирующей пробу струи; 6 - аналитическая зона плазмы до слияний струй; 7 - аналитическая зона плазмы после слияния струй [25]

Fig. 1. Plasmatron electrode unit and analytical zones of the plasma: 1,2-plasma torches; 3, 4- flows of the plasma-forming jets; 5 - flow of the sample transporting jet; 6 - analytical zone of the plasma before the jets confluence; 7 - analytical zone of the plasma after jets confluence [25]

30 мг, время полной экспозиции 6.5 с, время базовой экспозиции 100 мс. Для определения РЗЭ использовали дифракционную решетку 1200 шт/мм, что позволило снимать спектры в диапазоне от 280 до 545 нм.

Для управления прибором, обработки спектров и статистической обработки результатов анализа использовалось программное обеспечение «Атом» («ВМК «Оптоэлектроника»») [26].

\section{Материалы и реактивы}

Для пробоподготовки (разбавления) образцов использовали спектрально чистый графитовый порошок (ГП) (ос.ч., ГОСТ 23463-79). Для построения градуировочных графиков был взят отраслевой стандартный образец ОСО 250-91 (НФС-23, руда редкоземельная, ВИМС, Россия). 


\section{Пробоподготовка образиов}

Стандартный образец (СО) обладает очень высокими концентрациями РЗЭ (табл. 1), поэтому во избежание эффекта самопоглощения аналитического сигнала, характерного при высоких концентрациях элемента [27], данный образец был разбавлен ГП в 5 раз. Была приготовлена серия градуировочных образцов, полученная последовательным разбавлением стандартного образца ГП в 3 раза тремя стадиями (табл. 1). Образец руды Томторского месторождения разбавлялся графитовым порошком в 3 раза.

Таблица 1. Содержания РЗЭ (ppm) в образце ТМ-96 по данным ИСП-МС и ДДП-АЭС

Table 1. The REE contents (ppm) in TM-96 sample according to ICP-MS and TJP-OES

\begin{tabular}{|c|c|c|c|c|c|c|c|c|}
\hline \multirow{2}{*}{ Элемент } & \multirow{2}{*}{ ИСП-МС } & \multicolumn{5}{|c|}{ ДДП-АЭС } & \multirow{2}{*}{$t_{\text {расч }}$} & \multirow{2}{*}{$\mathrm{t}_{\text {табл }}$} \\
\hline & & $\mathrm{C}_{1} \pm \Delta_{1}$ & $\delta_{1}, \%$ & $\mathrm{C}_{2} \pm$ & & $\delta_{2}, \%$ & & \\
\hline $\mathrm{La}$ & 10800 & $10800 \pm 2200$ & 20 & $10800 \pm 500$ & (10) & 5 & 0.10 & 2.26 \\
\hline $\mathrm{Ce}$ & 22800 & $22000 \pm 16000$ & 73 & $22700 \pm 300$ & (11) & 2 & 0.74 & 2.23 \\
\hline $\operatorname{Pr}$ & 2300 & $2200 \pm 1400$ & 64 & $2200 \pm 100$ & (9) & 5 & 1.99 & 2.31 \\
\hline $\mathrm{Nd}$ & 8000 & $8100 \pm 5000$ & 62 & $8300 \pm 600$ & (11) & 8 & 1.33 & 2.23 \\
\hline $\mathrm{Sm}$ & 2700 & $2400 \pm 1400$ & 58 & $2500 \pm 300$ & (5) & 12 & 1.96 & 2.78 \\
\hline $\mathrm{Eu}$ & 1000 & $1250 \pm 750$ & 60 & $1100 \pm 300$ & (4) & 27 & 1.49 & 3.18 \\
\hline $\mathrm{Gd}$ & 3500 & $3700 \pm 3300$ & 89 & $3800 \pm 300$ & (8) & 8 & 2.36 & 2.37 \\
\hline $\mathrm{Tb}$ & 580 & $390 \pm 260$ & 67 & $430 \pm 80$ & (5) & 19 & 5.17 & 2.78 \\
\hline Dy & 3000 & $2600 \pm 1400$ & 54 & $2600 \pm 400$ & (4) & 16 & 2.61 & 3.18 \\
\hline Ho & 510 & $390 \pm 140$ & 36 & $400 \pm 100$ & (3) & 25 & 4.07 & 4.30 \\
\hline $\mathrm{Er}$ & 980 & $1200 \pm 900$ & 75 & $990 \pm 330$ & (3) & 34 & 0.03 & 4.30 \\
\hline $\mathrm{Tm}$ & 115 & - & - & - & & - & - & - \\
\hline $\mathrm{Yb}$ & 570 & $500 \pm 300$ & 60 & $460 \pm 90$ & (3) & 20 & 4.70 & 4.30 \\
\hline $\mathrm{Lu}$ & 71 & $14 \pm 11$ & 79 & $12 \pm 5$ & (3) & 42 & 50 & 4.30 \\
\hline
\end{tabular}

Примечание: $\mathrm{C}_{1}, \Delta_{1}, \delta_{1}$ - среднее содержание, погрешность и относительная погрешность, полученные методом ДДПАЭС по основным аналитическим линиям РЗЭ $(\mathrm{n}=3) ; \mathrm{C}_{2}, \Delta_{2}, \delta_{2}$ - среднее содержание, погрешность и относительная погрешность, полученные методом ДДП-АЭС по нескольким аналитическим линиям РЗЭ, в скобках указано количество аналитических линий, использованных для расчета $\mathrm{C}_{2}, \Delta_{2}, \delta_{2} ; \mathrm{t}_{\text {расч }}$ - расчетное значение критерия

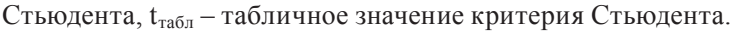

\section{Контроль правильности}

Образец руды был параллельно проанализирован методом ИСП-МС после сплавления с пероксидом натрия $\mathrm{Na}_{2} \mathrm{O}_{2}$. Методика сплавления описана в работе [28], методика определения методом масс-спектрометрии с индуктивно связанной плазмой (ИСП-МС), реализованная в «ЦКП Многоэлементных и изотопных исследований СО РАН» на масс-спектрометре высокого разрешения ELEMENT (Finnigan MAT, Германия), описана в работе [29].

\section{Результаты и их обсуждение}

Для определения содержаний РЗЭ были выбраны основные аналитические линии (табл. 2) с учетом их интенсивности излучения и возможных спектральных влияний со сто- 
Таблица 2. Основные аналитические линии РЗЭ и их интенсивность, содержания РЗЭ (ppm) в исходном стандартном образце и градуировочных образцах

Table 2. Main spectral lines of REE and their intensity, the contents of REE (ppm) in initial certified reference material and calibration samples

\begin{tabular}{|c|c|c|c|c|c|c|c|}
\hline \multirow{2}{*}{ Элемент } & \multirow{2}{*}{$\lambda, \mathrm{Hм}$} & \multirow{2}{*}{ I, отн.ед. } & \multirow{2}{*}{$\begin{array}{c}\text { Стандартный } \\
\text { образец }\end{array}$} & \multicolumn{4}{|c|}{ Градуировочные образцы } \\
\cline { 5 - 8 } & & & $1 / 5$ & $1 / 5 / 3$ & $1 / 5 / 9$ & $1 / 5 / 27$ \\
\hline $\mathrm{La}$ & 326.567 & 550 & 54700 & 10940 & 3647 & 1216 & 405 \\
\hline $\mathrm{Ce}$ & 321.894 & 710 & 108100 & 21620 & 7207 & 2402 & 801 \\
\hline $\mathrm{Pr}$ & 424.101 & 960 & 11500 & 2300 & 767 & 256 & 85 \\
\hline $\mathrm{Nd}$ & 372.350 & 780 & 36700 & 7340 & 2447 & 816 & 272 \\
\hline $\mathrm{Sm}$ & 373.920 & 2900 & 4400 & 880 & 293 & 98 & 33 \\
\hline $\mathrm{Eu}$ & 420.505 & 60000 & 1230 & 246 & 82 & 27 & 9 \\
\hline $\mathrm{Gd}$ & 343.999 & 2700 & 2600 & 520 & 173 & 58 & 19 \\
\hline $\mathrm{Tb}$ & 351.386 & 290 & 390 & 78 & 26 & 9 & 3 \\
\hline $\mathrm{Dy}$ & 357.624 & 4400 & 1700 & 340 & 113 & 38 & 13 \\
\hline $\mathrm{Ho}$ & 406.509 & 1700 & 300 & 60 & 20 & 7 & 2 \\
\hline $\mathrm{Er}$ & 400.797 & 14000 & 660 & 132 & 44 & 15 & 5 \\
\hline $\mathrm{Yb}$ & 369.419 & 32000 & 450 & 90 & 30.0 & 10.0 & 3.3 \\
\hline $\mathrm{Lu}$ & 337.650 & 6200 & 80 & 15 & 5.3 & 1.8 & 0.6 \\
\hline
\end{tabular}

Примечание: $\lambda$ - аналитическая линия; I - интенсивность аналитической линии. 1 / 5 / 3 - этапы разбавления исходного стандартного образца спектральным буфером в два шага. Первое разбавление исходного стандарта в 5 раз и последующее разбавление полученной смеси в $3,9,27$ раз соответственно.

роны других элементов. Известно, что основной проблемой при выборе аналитических линий Р3Э является именно наложение линий других элементов $[12,30]$. Большой регистрируемый спектральный диапазон (280-540 нм), реализованный в приборе, позволяет выбирать линии с минимальными наложениями линий других элементов. Определение Р3Э по наиболее интенсивным аналитическим линиям, традиционно применяемым при атомно-эмиссионном анализе [31, 32], затруднено из-за ураганных содержаний элементов и, соответственно, спектральных влияний.

Градуировочные графики для основных аналитических линий РЗЭ (рис. 2), построенные по стандартному образцу ОСО 250-91 (НФС-23, табл. 2), обеспечивают хорошую концентрационную зависимость: углы наклона графиков ( $\alpha$ ) близки к 45 градусам (рис. 2). В рамках данного исследования не проводилась оценка пределов обнаружения изучаемых элементов. Приведенные на рис. 2 значения $\mathrm{C}_{\min }$ соответствуют концентрациям элементов в градуировочном образце 1 / 5 / 27. Известно, что при анализе руд редких и редкоземельных элементов методом ДДП-АЭС пределы обнаружения РЗЭ ухудшаются на 2-3 порядка из-за спектральных влияний [12]. В данной работе спектральные влияния частично устраняли разбавлением образцов ГП. Кроме того, это позволяет решить другие проблемы: устраняется эффект самопоглощения аналитического сигнала при высоких концентрациях РЗЭ; для аналитических линий с высокими интенсивностями излучения уменьшается шанс «зашкаливания» (превышения порога возможностей электроники по приему и обработке сигнала) аналитического сигнала при регистрации детектором; выравнивается распределение температуры в плазме [27]. 


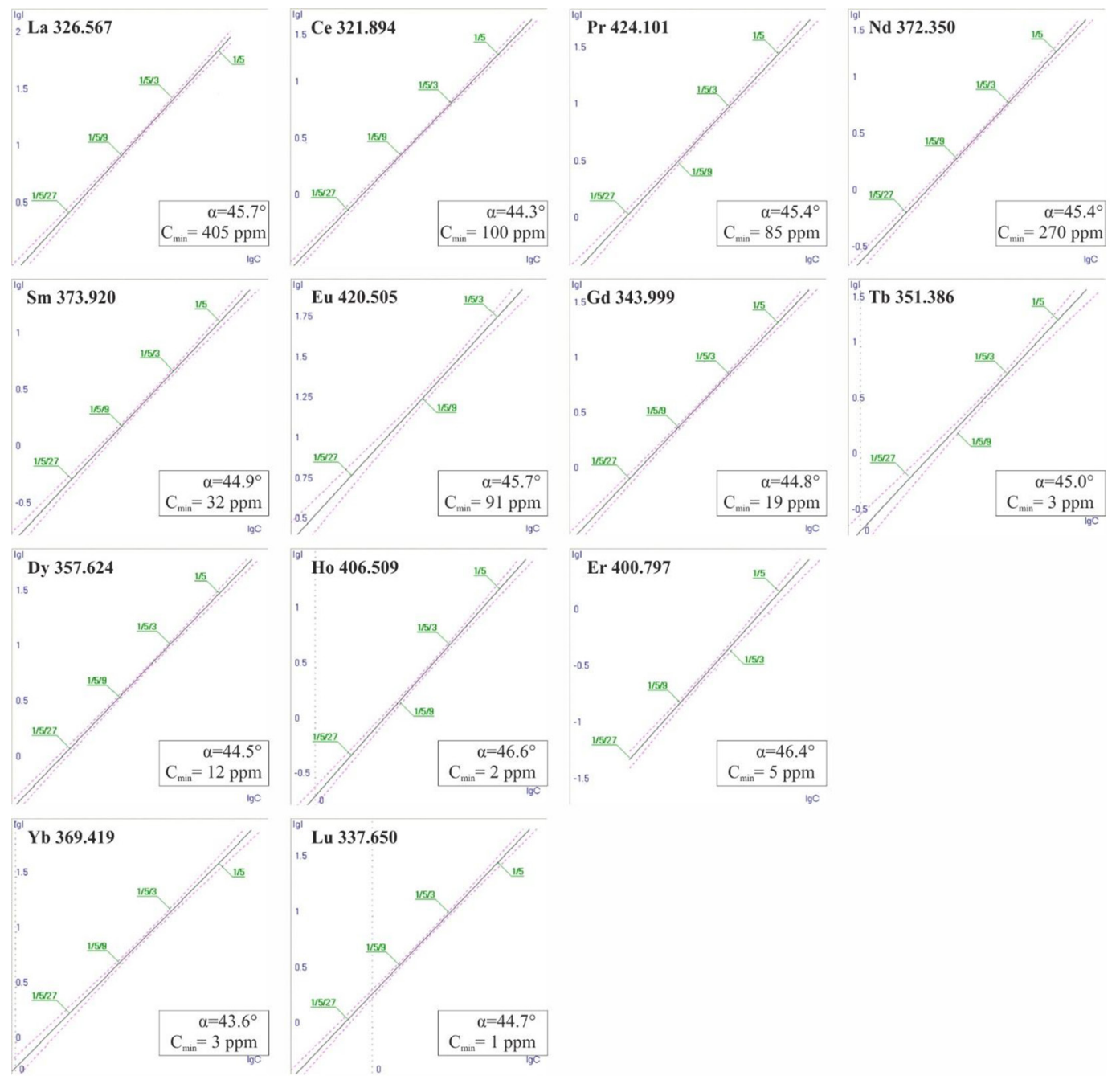

Рис. 2. Градуировочные графики для основных аналитических линий РЗЭ. В рамках указаны характеристики графиков: $\alpha$ - угол наклона градуировочного графика; $\mathrm{C}_{\min }-$ минимальное достоверно определяемое содержание элемента

Fig. 2. The calibration curves for the main spectral lines of REE. The characteristics of the curves are indicated within the frames: $\alpha$ - the slope of the calibration curve; $\mathrm{C}_{\min }-$ the minimum reliably determined content of the element

Некоторые элементы, такие как Tm, Y, Sc, относящиеся к числу РЗЭ [6], не определялись в рамках данного исследования из-за инструментальных ограничений. Определение содержаний остальных Р3Э по основным аналитическим линиям $\left(\mathrm{C}_{1}\right.$, табл. 1$)$ также было сопряжено с рядом трудностей, которые привели к увеличению погрешности анализа $\left(\Delta_{1}\right.$, табл. 1$)$. Относительная погрешность анализа ( $\delta_{1}$, табл. 1$)$ варьирует от 20 до $89 \%$. Таким образом, сравнение результатов ДДП-АЭС с данными ИСП-МС будет некорректно.

Высокая погрешность вызвана, прежде всего, большим разбросом содержаний элемента при параллельных измерениях, что вероятно вызвано недостаточной однородностью вещества и крупностью частиц минералов-носителей РЗЭ. Известно, что для эффективного испарения 
пробы в плазме необходимо тщательное истирание пробы: дисперсность образца должна составлять как минимум 0.025 мм, а дисперсность образца, содержащего «упорные» минералы, менее 0.005 мм [33].

Для повышения точности результатов анализа был использован подход, реализованный в работе [14]. Содержания РЗЭ были рассчитаны как среднее по нескольким аналитическим линиям $\left(\mathrm{C}_{2}\right.$, табл. 1). Для каждого элемента использовалась выборка аналитических линий с хорошими градуировочными графиками ( $\alpha$, близкое к $\left.45^{\circ}\right)$. В качестве примера в табл. 3 пред-

Таблица 3. Содержания Се в образце ТМ-96, полученные по разным аналитическим линиям

Table 3. The REE contents in the TM-96 sample obtained from various spectral lines

\begin{tabular}{|c|c|c|}
\hline$\lambda$, нм & I, отн.ед. & Содержание, ppm (n=3) \\
\hline Ce 320.171 & 990 & 22900 \\
\hline Ce 321.894 & 710 & 22000 \\
\hline Ce 356.080 & 1200 & 22800 \\
\hline Ce 365.585 & 1800 & 22800 \\
\hline Ce 394.215 & 2000 & 22100 \\
\hline Ce 394.275 & 2700 & 22900 \\
\hline Ce 404.076 & 2100 & 22000 \\
\hline Ce 408.122 & 670 & 23600 \\
\hline $\mathrm{Ce} 414.500$ & 670 & 22900 \\
\hline Ce 424.868 & 1100 & 23000 \\
\hline Ce 456.236 & 2100 & 22100 \\
\hline $\mathrm{Ce} 462.816$ & 1700 & 22200 \\
\hline
\end{tabular}

Примечание: $\lambda$ - аналитическая линия элемента; I - интенсивность аналитической линии.

ставлены результаты по церию, для расчёта среднего содержания которого было использовано 11 линий. Количество линий, использованных для расчета среднего содержания других РЗЭ, представлено в табл. 1. Погрешность и относительная погрешность анализа при использовании данного подхода ниже $\left(\Delta_{2}, \delta_{2}\right.$, табл. 1). Полученные таким образом содержания элементов были сопоставлены с результатами ИСП-МС. Правильность результатов анализа, полученных методом ДДП-АЭС, оценивали по величине критерия Стьюдента, рассчитанного для каждого элемента, и с допущением, что результаты ИСП-МС являются «аттестованными» (формула 1). Если расчётная величина критерия Стьюдента $\left(\mathrm{t}_{\text {расч}}\right)$ меньше табличного $\left(\mathrm{t}_{\text {табл}}\right.$, для степеней свободы $\mathrm{f}=\mathrm{n}-1$ и доверительной вероятности $\mathrm{P}=0.95)$, то систематическая ошибка определения отсутствует или незначима:

$$
t=\frac{\left|\mathrm{C}_{\text {ддП-АэС }}-\mathrm{C}_{\text {ИСП-мС }}\right| * \sqrt{n}}{s}<t(P, f),
$$

где $n$ - количество (выборка) спектральных линий, использованных для расчёта среднего содержания; $s$ - стандартное отклонение выборки [34].

$$
-66-
$$



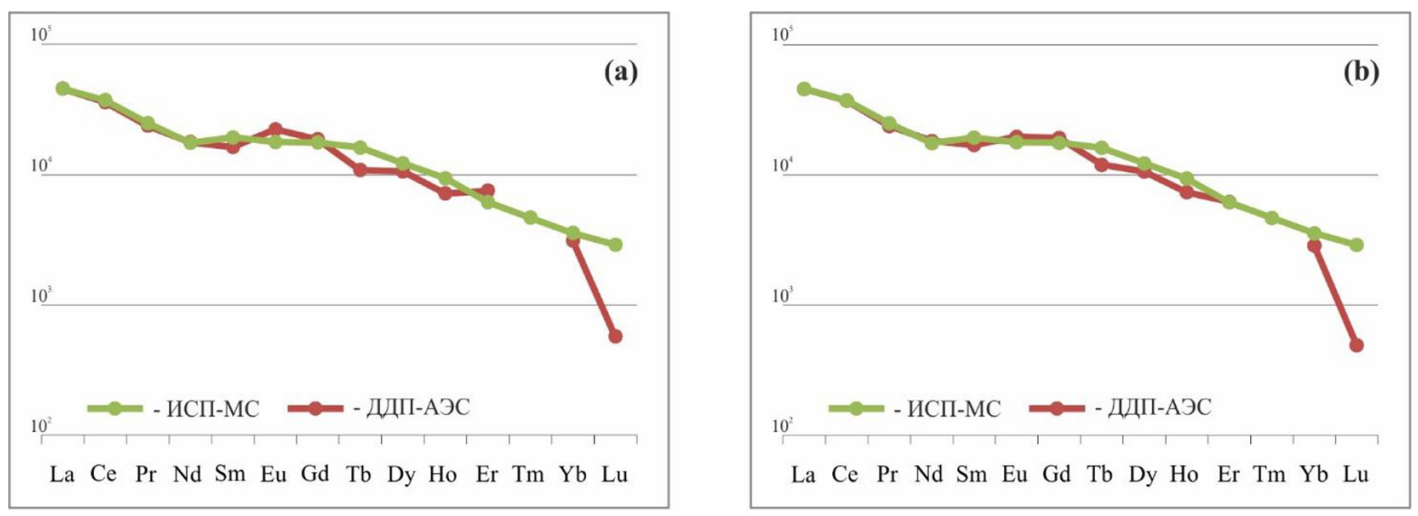

Рис. 3. Нормированные на карбонатный хондрит [35] спектры содержаний РЗЭ в образце ТМ-96, полученные методами ИСП-МС и ДДП-АЭС. Содержания РЗЭ методом ДДП-АЭС получены по основным аналитическим линиям (а) и содержания РЗЭ методом ДДП-АЭС получены по нескольким аналитическим линиям (b)

Fig. 3. Carbonaceous chondrite-normalized [35] spectra of the REE contents in TM-96 sample obtained by the ICP-MS and TJP-OES. (a) REE contents by the TJP-OES obtained from the main analytical lines and (b) REE contents by the TJP-OES obtained from several analytical lines

Результаты определения всех Р3Э, за исключением $\mathrm{Tb}, \mathrm{Yb}$ и $\mathrm{Lu}$, являются правильными. Занижение результатов по $\mathrm{Tb}, \mathrm{Yb}$ и Lu связано с тем, что эти элементы имеют малое количество аналитических линий в анализируемом спектральном диапазоне с высокими относительными интенсивностями излучения. Этот фактор, в совокупности с небольшими содержаниями данных элементов в образце при высоких содержаниях других РЗЭ, оказывающих мешающее влияние (наложение аналитических линий других РЗЭ с более высокими относительными интенсивностями), создает проблемы с определением $\mathrm{Tb}, \mathrm{Yb}$ и $\mathrm{Lu}$.

По полученным данным были построены спектры, нормированные по карбонатному хондриту (рис. 3) [35], которые нагляднее демонстрируют правильность результатов, полученных методом ДДП-АЭС.

\section{Заключение}

Оценены возможности метода ДДП-АЭС для анализа рудных содержаний РЗЭ в геологических образцах. На примере образца редкоземельной руды (ТМ-96) из Томторского ниобийредкоземельного месторождения показано, что метод позволяет достоверно определять содержания следующих P3Э: La, Ce, Pr, Nd, Sm, Eu, Gd, Dy, Но и Er. Однако при определении Tb, $\mathrm{Yb}, \mathrm{Lu}$ выявлена систематическая ошибка, занижающая истинные содержания этих элементов в образцах. Необходимы дальнейшие исследования по совершенствованию не только методики анализа, но инструментального обеспечения метода. Возможности метода и отсутствие необходимости проводить предварительную химическую пробоподготовку делают этот метод быстрым и эффективным. Полученные данные позволяют использовать метод для рутинного определения большого количества проб, необходимого для статистического анализа. 


\section{Благодарности / Acknowledgments}

Работа выполнена при поддержке РНФ № 18-17-00120. Аналитические работы проведены в «ЦКП Многоэлементных и изотопных исследований СО РАН».

The study was supported by grant 18-77-10056 from the Russian Science Foundation. The analyses were performed at the Analytical Center for multi-elemental and isotope research SB RAS (Novosibirsk, Russia).

\section{Список литературы / References}

1. Аношин Г. Н., Заякина С.Б. Химический анализ в геологии и геохимии. Под ред. Аношина Г.Н. Новосибирск: Академическое изд-во «Гео», 2016. 614 с. [Anoshin G.N., Zayakina S. B. Chemical analysis in geology and geochemistry. Under Ed. Anoshin G. N. Novosibirsk: The Academic Publishing House «Geo», 2016. 614 p. (in Russ.)]

2. Zayakina S. B., Anoshin G. N. Comparison between the distributions of excitation temperatures and the analytical line intensities of noble metals in two-jet arc plasmatrons used in atomic emission analysis. High Energy Chemistry 2007, Vol. 41(4), P. 274-278.

3. Nikolaeva I. V., Palesskiy S. V., Karpov A.V. Analysis of geological samples: comparison of solution ICP-MS and fused glasses LA-ICP-MS techniques. Bulletin of the Tomsk polytechnic university-geo assets engineering 2019. Vol. 330(5), P. 26-34.

4. Zawisza B., Pytlakowska K., Feist B., Polowniak M., Kita A., Sitko R. Determinition of rare earth elements by spectroscopic techniques: a review. JAAS: Journal of Analytical Atomic Spectrometry 2011. Vol. 26(12), P. 2373-2390.

5. Gorbatenko A. A., Revina E. I. A review of instrumental methods for determination of rare earth elements. Inorganic materials 2014. Vol. 51(14), P. 1375-1388.

6. Balaram V. Rare earth elements: A review of applications, occurrence, exploration, analysis, recycling, and environmental impact. Geoscience Frontiers 2019. Vol. 10(4), P. 1285-1303.

7. Pinto F. G., Junior R. E., Saint'Pierre T.D. Sample preparation for determination of rare earth elements in geological samples by ICP-MS: a critical review. Analytical letters 2012. Vol. 45(12), P. $1537-1556$.

8. Горбатенко А.А., Ревина Е.И. Инструментальные методы определения редкоземельных элементов (обзор). Заводская лаборатория. Диагностика материалов. 2014. Т. 80, № 4, С. 7-19. [Gorbatenko A.A., Revina E.I.. Instrumental Methods for Determination of Rare Earth Elements (Review). Industrial laboratory. Diagnostics of materials. 2014. Vol. 80(4), P. 7-19. (In Russ.)]

9. Ganjali M.R., Gupta V.K., Faridbod F., Norouzi P. Lanthanides Series Determinination by Various Analutical Methods. Elsevier. 2016. P. 189-214.

10. Заксас Н. П., Веряскин А.Ф., Лабусов В.А. Возможности двухструйной дуговой плазмы для прямого анализа проб разной природы. Заводская лаборатория. Диагностика материалов. 2017. T. 83(1), С. 86-88. [Zaksas N.P., Verjaskin A.F., Labusov V.A. Assessment of the Capabilities of Using a Two-Jet Arc Plasma for Direct Analysis of the Samples of Different Nature. Industrial laboratory. Diagnostics of materials 2017. Vol. 83(1), P. 86-88. (In Russ.)]

11. Yudelevich I. G., Cherevko A. S., Engelsht V. S., Pikalov V. V., Tagiltsev A. P., Zheenbajev Z.Z. A two-jet plasmatron for the spectrochemical analysis of geological samples. Spectrochimica Acta Part B: Atomic Spectroscopy 1984. Vol. 39(6), P. 777-785. 
12. Brykin A.V., Kolegov K.A., Frtemov A.V. Analysis of the market of Rare-Earth elements (rees) and ree catalysts. Catalysis in industry. 2014. Vol. 1(1), P. 7.

13. Zaksas N. P., Shelpakova I. R., Gerasimov V. G. Determination of trace elements in different powdered samples by atomic emission spectrometry with spectral excitation in a two-jet arc plasmatron. Journal of Analytical Chemistry 2004. Vol. 59(3), P. 222-228.

14. Заякина, С. Б., Аношин, Г.Н. Определение бора в геологических пробах атомноэмиссионным спектральным методом с применением дугового двухструйного плазмотрона. Аналитика и контроль 2010. T. 14(2), C. 87-94. [Zayakina S.B., Anoshin G. N. Determination of boron at the geological samples by atomic emission spectroscopy with using two-jet arc plasmotron. Analytics and control 2010. Vol. 14(2), P. 87-94. (In Russ.)]

15. Черевко А. С., Сысо А.И. Использование многоэлементного атомно-эмиссионного спектрографического анализа природных объектов в эколого-агрохимических исследованиях. Агрохимия 2010. № 11, С. 70-79. [Cherevko A. S., Syso A. I. Multielement atomic emission spectrographic analysis of natural objects in environmental and agrochemical research. Agrokhimiya 2010. № 11, P. 70-79. (In Russ.)]

16. Шавекин А.С., Купцов А.В., Заякина С. Б., Аношин Г.Н. Сравнение результатов сцинтилляционного атомно-эмиссионного анализа, полученных с использованием установки «Поток» и дугового плазмотрона «Факел». Заводская лаборатория. Диагностика материалов 2017. T. 83(1), C. 97-101. [Shavekin A. S., Kuptsov A. V., Zayakina S. B., Anoshin G. N. Comparison of the Results of Scintillation Atomic Emission Analysis Obtained on Spectral System «Potok» and a TwoJet Arc Plasmatron «Fakel». Industrial laboratory. Diagnostics of materials 2017. Vol. 83(1), P. 97-101. (In Russ.)]

17. Lazareva E. V., Zhmodik S.M., Dobretsov N.L., Tolstov A. V., Shcherbov B.L., Karmanov N. S., Gerasimov E. Yu., Bryanskaya A. V. Main minerals of abnormally high-grade ores of the Tomtor deposit (Arctic Siberia). Russian geology and geophysics 2015. Vol. 56(6), P. 844-873.

18. Коноплев А.Д., Толстов А.В., Васильев А.Т., Нечелюстов Г.Н., Кузьмин В.И., Скляднева В.М., Дубинчук В.Т., Коноплева Е.В., Сидоренко Г.А. Особенности локализации редкометального оруденения на месторождении Томтор. Редкометально-урановое рудообразование в осадочных породах. М., Наука, 1995, С. 223-241. [Konoplev А.D., Tolstov A. V., Vasil'ev A.T., Nechelyustov G. N., Kuz'min V.I., Sklyadneva V. M., Dubinchuk V. T., Konopleva E. V., Sidorenko G. A. Peculiarities of localization of rare-metal mineralization at the Tomtor deposit. Rare-metal-uranium ore formation in sedimentary rocks. M., Nauka, 1995, P. 223241. (In Russ.)]

19. Минерагения кор выветривания карбонатитов. Методическое руководство. Под ред. Н.В. Межеловского. М.: ГЕОКАРТ, ГЕОС, 2011. 308 c. [Minerageny of carbonatite weathering crust. Methodical guide / Under Ed. Mezhelovsky N. V. Moscow, GEOKART, GEOS, 2011. 308 p. (In Russ.)]

20. Павлычева Н.К. Спектральные приборы с неклассическими дифракционными решетками. Казань: Изд. КГТУ, 2003. 197 с. [Pavlycheva N. K. Spectral instruments with non-classical diffraction gratings. Kazan, Ed. KSTU, 2003. 197 p. (In Russ.)]

21. Павлычева Н.К. Применение анализаторов МАЭС в промышленности. Материалы V Международного симпозиума по прикладной геохимии стран СНГ. Новосибирск, 2004. С. $24-$ 
34. [Pavlycheva N.K. Application of MAES analyzers in industry. Materials of the V International Symposium on Applied Geochemistry of the CIS countries. Novosibirsk, 2004. P. 24-34. (In Russ.)]

22. Заякина С. Б., Аношин Г.Н., Путьмаков А.Н. Модернизация дифракционного спектрографа ДФС-458: расширение возможностей атомно-эмиссионного спектрального анализа. Analytics and control 2005. T. 9(2), С. 212-219. [Zayakina S.B., Anoshin G.N., Putmakov A. N. Improvement of DFS-458 diffraction spectrograph: extension of analytical capabilities of atomic-emission spectral analysis. Analytika i kontrol 2005. Vol. 9(2), P. 212-219. (In Russ.)]

23. Патент 55525 РФ. Герасимов В.А., Лабусов В. А., Саушкин М.С. (ООО «ВМКОптоэлектроника», Новосибирск). Двухструйный дуговой плазматрон для атомноэмиссионного спектрального анализа. Опубл. 10.08.2006. [Patent 55525 RU. Gerasimov V.A., Labusov V.A., Saushkin M. S. (LLC «VMK-Optoelektronika», Novosibirsk). Two-jet arc plasmatron for atomic emission spectral analysis. Publ. Date 10.08.2006. (In Russ.)]

24. Патент 2298889 РФ. Герасимов В.А., Лабусов В.А., Саушкин М.С.(ООО «ВМКОптоэлектроника», Новосибирск). Двухструйный дуговой плазматрон для атомноэмиссионного спектрального анализа. Опубл. 10.05.2007. [Patent 2298889 RU. Gerasimov V.A., Labusov V.A., Saushkin M. S. (LLC «VMK-Optoelektronika», Novosibirsk). Two-jet arc plasmatron for atomic emission spectral analysis. Publ. Date 10.05.2007. (In Russ.)]

25. Заксас Н. П., Веряскин А.Ф. Двухструйная дуговая плазма: матричные влияния и способы их подавления. Заводская лаборатория. Диагностика материалов 2019. Т. 85(1). С. 139144. [Zaksas N.P., Veryaskin A.F. A two-jet arc plasma: matrix effects and ways to their suppression. Industrial laboratory. Diagnostics of materials 2019. Vol. 85(1), P. 139-144. (In Russ.)]

26. Гаранин А.А., Неклюдов О.А., Петроченко Д.В., Семёнов 3.В., Шаталов И.Г., Панкратов С.В. Программное обеспечение атомно-эмиссионного спектрального анализа (программа «Атом»). Заводская лаборатория. Диагностика материалов 2012. Т. 78(12), C. 69-74. [Garanin A.A., Neklyudov O.A., Petrochenko D.V., Semenov Z.V., Shatalov I.G., Pankratov S. V. Software for atomic-emission spectral analysis («Atom»). Industrial Laboratory. Diagnostics of Materials 2012. Vol. 78(1-2), Р. 69-74. (In Russ.)]

27. Евдокимов И.И., Пименов В.Г. Определение примесей в особо чистых нанопорошках оксида иттрия, легированного неодимом, методом атомно-эмиссионной спектрометрии с индуктивно связанной плазмой. Аналитика и контроль 2013. Т. 17. № 2, С. 170-176. [Evdokimov I. I., Pimenov V.G. Determination of impurities in highly pure neodymium-doped yttrium oxide nanopowders by inductively coupled plasma atomic emission spectrometry. Analytics and control. 2013. Vol. 17(2), P. 170-176. (In Russ.)]

28. Saryg-ool B. Yu., Bukreeva L.N., Myagkaya I.N., Tolstov A. V., Lazareva E. V., Zhmodik S. M. Influence of sample digestion on the determination of high contents of rare-earth and high field strength elements in geological samples by ICP-AES and ICP-MS (case study of the Tomtor deposit). Journal of Siberian Federal University. Chemistry 2020. Vol. 13(4). In press.

29. Жерноклеева К. В., Барановская В.Б. Анализ чистых скандия, иттрия и их оксидов методами атомно-эмиссионной спектрометрии с индуктивно связанной плазмой и массспектрометрии с индуктивно связанной плазмой. Заводская лаборатория. Диагностика материалов. 2010. Т. 76. № 11, С. 20-26. [Zhernokleeva K. V., Baranovskaya V. B. Analysis of pure scandium, yttrium and their oxides by inductively coupled plasma atomic emission spectrometry and 
inductively coupled plasma mass spectrometry. Industrial Laboratory. Diagnostics of Materials 2010. Vol. 76(11), P. 20-26. (In Russ.)]

30. Карандашев В.К., Жерноклеева К. В., Барановская В. Б., Карпов Ю. А. Анализ высокочистых материалов методом масс-спектрометрии с индуктивно связанной плазмой (обзор). $3 a-$ водская лаборатория. Диагностика материалов 2012. Т. 78. № 1, С. 17-30. [Karandashev V.K., Zhernokleeva K.V., Baranovskaya V.B., Karpov Yu.A. Analysis of high-purity materials by inductively coupled plasma mass spectrometry (review). Industrial Laboratory. Diagnostics of Materials 2012. Vol. 78(1), P. 17-30. (In Russ.)]

31. Карандашев В.К., Жерноклеева К.В., Барановская В.Б., Туранов А.Н., Карпов Ю.А. Определение примесей тугоплавких металлов в редкоземельных металлах и их соединениях. Журнал аналитическойхимии 2012. T. 67. № 4, С. 383-392. [Karandashev V. K., Zhernokleeva K. V., Baranovskaya V.B., Turanov A. N., Karpov Yu. A. Journal of Analytical Chemistry. 2012. Vol. 67(4), P. 383-392 (In Russ.)]

32. Ticová B., Novotný K., Kanický V. Comparison of different spectral resolution ICP-OES spectrometers for the determination of rare earth elements. Chemical Papers 2019. Vol. 73(12), P. 2913-2921.

33. Cherevko A.S. Mechanism of the evaporation of particles of powder test materials in the discharge of a two-jet argon arc plasmatron. Journal of Analytical Chemistry 2011. Vol. 66(7), P. 610619 .

34. Государственная фармакопея Российской Федерации. XIV изд-е. Т. 1. М.: МЗРФ, 2018. 1814 c. [State Pharmacopoeia of the Russian Federation. XIV ed. Vol. 1. Moscow: Ministry of Health of the Russian Federation, 2018. 1814 p. (In Russ.)]

35. McDonough W. F., Sun, S.S. The composition of the Earth. Chemical geology 1995. Vol. 120(3-4), P. 223-253. 